\title{
Review of Secondary Consolidation of Structured Soft Soil
}

\author{
Binbin $\mathrm{Xu}^{1, \mathrm{a}}$ and Linbo $\mathrm{Xie}^{2, \mathrm{~b}}$ \\ ${ }^{1}$ Tianjin Port Engineering Institute Ltd. of CCCC, Tianjin, China; Key Lab. of Geotechnical \\ Engineering of Tianjin, Tianjin, China; Key Lab. of Geotechnical Engineering, Ministry of \\ Communication, Tianjin, China \\ ${ }^{2}$ Tianjin Port Engineering Institute Ltd. of CCCC, Tianjin, China; Key Lab. of Geotechnical \\ Engineering of Tianjin, Tianjin, China; Key Lab. of Geotechnical Engineering, Ministry of \\ Communication, Tianjin, China \\ a xubinbin@tpei.com.cn, b xielinbo@tpei.com.cn
}

\begin{abstract}
Keywords: Secondary consolidation, Soil structure, Compressibility, Primary consolidation
Abstract. The mechanical response of natural sedimentary clay is very different from the usual clay due to its highly-developed structure. When the structured soil is loaded, its structure varies accordingly, which results in the corresponding variation of physical and mechanical properties of soft soil. If the soil parameters obtained from the remolded soils are used directly in the structured soil, significant mistake may be caused. The secondary consolidation occurs at the beginning of primary consolidation and becomes predominant at the end of primary consolidation.
\end{abstract}

\section{Background}

In the east-coastal area of China the soft marine soil is widely distributed which is the composition of clayey sedimentary or river flushing. Due to the shallow underground water line, the soft soil is of high water content, large compressibility, poor permeability and low bearing capacity. The coverage depth is usually very great and sometimes it may reach several dozens of meters. General speaking, the percentage of clay particle is very large and its plasticity index is over 17. Considering the special sedimentary environment and complex composition of soft soil, the mechanical response is also very different from the usual clay due to its highly-developed structure, such as high sensitivity, low strength and easy to be disturbed.

Meanwhile, it is more developed in the coastal area and many large engineering such as port, breakwater, storage tank, airport, railway and express highway have been built on such soft soil ground. Due to its slow drainage speed, the long-term settlement is always very difficult to deal with. For example, the Kansai international airport is built by the land reclamation in the sea to form an artificial island. There has been over $12 \mathrm{~m}$ settlement since its operation, which gives significant influence on the following maintenance. Now in the Hongkong-Zhuhai-Macau bridge engineering, there are also two artificial islands in the sea to connect the bridge passage and the immersed tube tunnel, its post-construction settlement is bound to be very important for the engineers. If there is no comprehensive and deep acquaintance to the natural sedimentary clay, it is impossible to forecast the long-term settlement precisely. In this paper, the previous research literatures of long-term settlement of soft soil ground is reviewed and the matters need to be intentioned are proposed.

\section{Obstruction of Secondary Consolidation Research}

Usually the soft soil in the shallow ground is reinforced through drainage consolidation such as vacuum preloading or surcharge preloading to satisfy the requirement of settlement during the construction and after the construction, which is usually called the primary consolidation analysis. Recently, huge engineering involved with urban track traffic, high-speed railway and artificial island comes forward continuously, which is very sensitive to the post-construction settlement, namely the long-term settlement. Compared with the primary consolidation settlement, the progress of secondary consolidation settlement developed very slow and it may ascribed to the following reasons: 
1) The research of secondary consolidation should be supported by plenty of laboratory experiments which need long time for each sample. The shortage of background documents restricts the research development.

2) The research of secondary consolidation mainly concentrates on the research of coefficient of secondary consolidation; however the coefficient is closely related to the category of soil, which restricts the application of research fruits.

3) Presently, the prediction of secondary consolidation settlement is mainly experiential and other method such as numerical computation is very rare.

\section{Influence of Soil Structure}

As the development of boring technology, the recognition to the natural structured soil is more and more thoroughly. Due to the structure, the mechanical response of natural soil is quite different from the corresponding fully remolded soil. For the geo-materials, the structure displays as the shape of soil particles and void ratio, the pattern of arrangement, the mechanical action among particles. When the structured soil is loaded, its structure varies accordingly, which results in the corresponding variation of physical and mechanical properties of soft soil. From the aspects of practical engineering, there may be two problems. If we ignore the structure of natural soil and only predict its response based on the fully remolded samples or disturbed samples, the stiffness and strength of natural soils may be underestimated so that the design may be relatively safe. On the other side, if we only recognize the low compressibility of natural soil under low stress level but neglect the significant compressibility when the stress is over the yield stress, the stiffness of natural soil would be overestimated, which may threaten the safety of the construction.

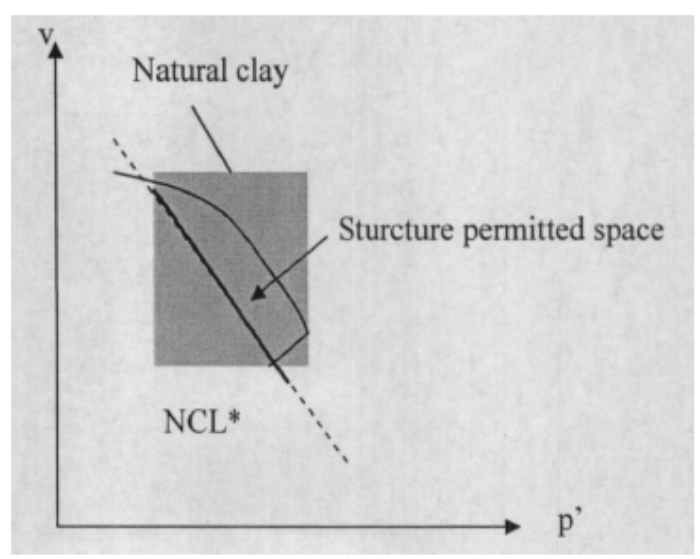

Figure 1 Sketch of structured permitted space of nature clay

Leroueil et al. [1] pointed that the structure of soil is the expression of sedimentary, load experience. For this view, any soil at any state should be more or less structured. Also he proposed four different state of soil corresponding to the structures: undisturbed state, destructured state, remolded state, resedimented state. The undisturbed state is the natural sedimentary state which is a complex proceeding. The destructured state corresponds to the variation of structure due to volumetrical or shearing deformation. The remolded state means that the soil is loaded enough so that the structure is fully destroyed. The resedimented state is the slurry state of remolded soil and it is depended on the mineral constituent, particle size, sedimentary rate and other environment. The remolded state can reflect the mineral constituent and sedimentary environment of natural soil. The variation from the undisturbed state to the destructured state until the remolded state represents the gradual loss of structure. The mechanical properties of remolded soil is the most essential characteristics. Leroueil and Vaughan [2] defined the concept of structured permitted space, as shown in Fig. 1, to demonstrate the relationship of three states. The influence of soil structure has been recognized in the early stage. Leroueil et al. $[2,3]$ proposed the concept of structure by comparing the 
natural soil and soft rock. The mechanical response of nature soil and remolded soil can be distinguished when considering the structure. Therefore, the structure of soil is as important as the initial void ratio, stress history to determine the mechanical property.

\section{Research of Secondary Consolidation}

The research of drainage consolidation using soil-water coupled theory based on effective stress principle has been gradually prefect and now the research point is focusing on the influence of constitutive relationship on the deformation of soil. Meanwhile plenty of practical engineering shows that there is always long-term settlement problems for the soft soil ground.

In order to explain and solve the problem of secondary consolidation, many researchers consider the effect of viscosity of the soil to analyze the consolidation process and settlement. Taylor [4] believed that the secondary consolidation would occur during and after the primary consolidation. Along with the Taylor's view, Suklje [5] and Bejerrum [6, 7] proposed the parallel e-logp' curve which is widely used in the following research. Barden [8] considered the non-linear rheology of soil in the consolidation theory and used the non-linear Kelvin model to simulate the non-linear consolidation properties and the coupled effect of primary and secondary consolidation, namely the non-linear rheology in the period of primary consolidation. Utilizing Eyring's theory of rate process [9], Wu et al. [10] established a non-linear rheology constitutive model and obtained the linear relationship between secondary deformation and the logarithmic time, which is accordance with the results of Crawford and Bjerrum. Bjerrum [7] proposed the concept of instant compression and delayed compression to describe the deformation of the soil skeleton when the pore water pressure exists. He believed that the delayed compression, namely the creep, exists in the whole consolidation stage and proposed the time lines model. Bjerrum also pays much attention to the influence of secondary settlement in the vertical drainage well and he believed that although the rate of primary consolidation is enlarged there is no reduction of secondary consolidation. Surcharge preloading may be one of the effective ways to reduce the long-term settlement. Yin and Graham [11] introduced the concept of the equivalent time as well as the physical explanation and mathematical definition and established one-dimensional equivalent-time rheology model to analyze the stress and strain properties of soil related with time effect. Borja et al [12] also adopted the concept of equivalent time to carry out a serial of two-dimensional visco-plastic analyses combined with stress-strain relationship proposed by Singh-Mitchell model and Biot's consolidation theory. Ryde [13] introduced the EVP constitutive model developed by Yin and Graham and carried out one-dimensional consolidation analysis considering vertical and radial seepage by finite difference method. The influence of creep, non-linear stiffness and permeability coefficient were considered. Nash et al. [14] established one-dimensional finite difference method to simulate the consolidation process of soft soil subjected to surcharge based on EVP model.

\section{Division of Primary and Secondary Consolidation}

Usually it is assumed that there is no secondary consolidation until the end of primary consolidation. However, such division method is promiscuous and controversial. First, it is dubitable for the judgment of dissipation of excess pore water pressure. The compression process is continues and the true threshold between primary consolidation and secondary consolidation is depend on the experiment method such as load ratio, load duration, sample thickness and soil structure etc. Then the commencement time of secondary consolidation is also controversial. According to the division of excess pore water pressure, the secondary consolidation begins after the primary consolidation. However, according to the mechanism of secondary consolidation, namely the creep behavior of soil skeleton under effective stress, the secondary consolidation should occur with the primary consolidation at the same time and its deformation become predominant near the end of primary consolidation. 


\section{Conclusions}

The long-term settlement of the soft soil ground is always the highlight both in the academic and engineering field. There are many methods to predict the secondary consolidation settlement. However, when the soil structure is considered, the problem seems to be more complex. This paper reviewed the research of secondary consolidation of structure soft soils and the conclusions are as follows:

1) The existence of soil structure makes its mechanical response quite different from the fully remolded soil. If the soil parameters obtained from the remolded soils are used directly in the structured soil, significant mistake may be caused.

2) The division of primary consolidation and secondary consolidation may be not correct based on the dissipation of excess pore water pressure and the secondary consolidation occurs at the beginning of primary consolidation and becomes predominant at the end of primary consolidation.

\section{Acknowledgements}

This work is supported by the Natural Science Foundation of Tianjin (16JCZDJC38800).

\section{References}

[1] S. Leroueil, F. Tavenas, J. Locat, Geotechnique, 35(2), (1985), p.223-226.

[2] S. Leroueil, P.R. Vaughan, Geotechnique, 40(3): (1990), 467-488.

[3] S. Leroueil, Journal of Geotechnical and Geoenvironmental Engineering, 123(9): 895-897.

[4] D.W. Taylor, London, Chapman\&Hall, New York, Wiley, 1948.

[5] L. Suklje, Proc. 4th Int. Conf. on SMFE, 1957, 1, 200-206.

[6] L. Bjerrum, Seventh Rankine Lecture. Geotechnique, 1967, 17(2): 81-118.

[7] L. Bjerrum, Purdue University, ASCE, 1972, 1: 1-54.

[8] L. Barden, Geotechnique, 1965, 15(4): 345-362.

[9] H. Eyring, Chem. Phys., 1936, 4, 283.

[10] T.H. Wu, D. Rasendiz, R.J. Neukirchner, ASCE, 1966, 92(SM6), 229-248.

[11] J.H. Yin, J. Graham, Canadian Geotechnical Journal, 1989, 26(2), 199-209.

[12] R.I. Borja, S.R. Lee, Computer Methods in Applied Mechanics and Engineering,1990, 78(1), 48-72.

[13] S.J. Ryde, PhD thesis, University of Bristol, 1997.

[14] D.F.T. Nash, S.J. Ryde, Geotechnique, 2001, 51(3), 257-273. 